\title{
二氧化碳还原转化
}

\author{
刘志敏 1 , 孙振宇 2 \\ 1 中国科学院化学研究所, 北京分子科学国家实验室, 胶体与界面与热力学重点实验室, 中国科学院化学研究所分子科学卓 \\ 越教育中心, 北京 100190 \\ 2 有机-无机复合材料国家重点实验室, 化学工程学院, 北京化工大学, 北京 100029
}

\section{Reductive Transformation of Carbon Dioxide}

\author{
Zhimin Liu ${ }^{1}$, Zhenyu Sun ${ }^{2}$ \\ ${ }^{1}$ Beijing National Laboratory for Molecular Sciences, Key Laboratory of Colloid and Interface and Thermodynamics, CAS \\ Research/Education Center for Excellence in Molecular Sciences, Institute of Chemistry, Chinese Academy of Sciences, Beijing \\ 100190, China. \\ ${ }^{2}$ State Key Laboratory of Organic-Inorganic Composites, College of Chemical Engineering, Beijing University of Chemical \\ Technology, Beijing 100029, China.
}

Emails: liuzm@iccas.ac.cn (Z.L.); sunzy@mail.buct.edu.cn (Z.S.)

Published online: December 17, 2020.

二氧化碳是一种主要温室气体, 也是来源丰 富、环境友好的可再生碳一资源。其化学转化不仅 可固定 $\mathrm{CO}_{2}$, 还可获得高附加值能源产品、化学品 以及可降解的高分子材料, 因此其资源化利用引 起了科技界的广泛关注和研究兴趣。本专刊中收 集了我国部分科学家在相关领域的研究成果, 将 展示通过热、电、光催化还原 $\mathrm{CO}_{2}$ 制备化学品和能 源产品方面的最新研究进展。

$\mathrm{CO}_{2} / \mathrm{H}_{2}$ 参与的羰基化反应可获得醇、羧酸、 胺、醛等大宗或精细化学品, 是二氧化碳还原转化 研究最为广泛的一个方向。孙予罕等 ${ }^{1}$ 系统总结了 过渡金属催化 $\mathrm{CO}_{2} / \mathrm{H}_{2}$ 参与的烯烃、卤代烃、甲醇及 其衍生物等羰基化反应的研究进展, 探讨了催化 反应机制, 并对未来发展方向进行了展望。何林 等 2 综述了近年来均相催化 $\mathrm{CO}_{2} / \mathrm{H}_{2}$ 参与的烯烃、 胺、醇/醚等羰基化反应研究及发展现状, 重点探 讨了不同种类的金属催化剂对反应过程的影响。

由于其气体特性, $\mathrm{CO}_{2}$ 参与的化学转化过程通 常涉及多相体系, 其中介质起重要作用。功能离子 液体在 $\mathrm{CO}_{2}$ 转化过程中, 不仅可用作反应介质, 还 可用作 $\mathrm{CO}_{2}$ 的吸附剂、活化剂, 进而催化 $\mathrm{CO}_{2}$ 转化。 刘志敏等 3 总结了离子液体介导的 $\mathrm{CO}_{2}$ 转化研究进 展, 探索了离子液体的作用, 以及离子液体催化体 系的催化反应机制。

二氧化碳加氢制甲醇受到广泛研究, 其实现工
业化的关键在于催化剂。刘国亮和洪昕林等 ${ }^{4}$ 以有机 框架材料 $\mathrm{UiO}-66$ 作为 $\mathrm{ZrO}_{2}$ 的前驱体, 将 $\mathrm{Cu}$ 纳米颗粒 限制在UiO-66的孔隙/缺陷内构建了 $\mathrm{Cu} / \mathrm{ZrO}_{2}$ 纳米复 合催化剂, 对 $\mathrm{CO}_{2}$ 加氢制甲醇显示高反应活性, 归 因于催化剂中含有大量的 $\mathrm{Cu}-\mathrm{ZrO}_{2}$ 活性界面。机理 研究发现该反应遵循甲酸盐为中间体的反应路 径。杨恒权等5 制备了三种具有不同强度金属-载体 相互作用的 $\mathrm{Cu} / \mathrm{ZnO}-\mathrm{SiO}_{2}$ 催化剂, 探究其催化性能, 发现 $\mathrm{Cu} / \mathrm{ZnO}$ 间强的相互作用引起了催化剂结构重 构, 促使体相中的 $\mathrm{ZnO}$ 物种向催化剂表面 $\mathrm{Cu}$ 物种迁 移, 形成了更多的 $\mathrm{Cu} / \mathrm{ZnO}$ 界面, 有利于甲醇的生成。

以水为氢源, 通过光、电催化实现 $\mathrm{CO}_{2}$ 还原, 能够从本质上解决氢来源问题, 是当前 $\mathrm{CO}_{2}$ 还原转 化的热点领域。其中, 电催化转化 $\mathrm{CO}_{2}$ 是将可再生 电能转化为化学能的有效途径。程涛等 6 系统总结 了二氧化碳电还原领域的理论研究进展和成果, 重 点关注反应机理的研究。铜催化剂因其在电化学 还原 $\mathrm{CO}_{2}$ 过程中可以产生高附加值的碳氢化合物 而受到广泛关注与研究。张生等 ${ }^{7}$ 介绍了近五年 $\mathrm{Cu}$ 基催化剂在选择性制备 $\mathrm{C}_{2+}$ 产物方面的研究进展, 概 述了可能的反应机理, 总结了影响产物选择性的 因素, 并对该领域未来研究方向进行了展望。汪国 雄等 ${ }^{8}$ 分析了三种 $\mathrm{CO}_{2}$ 电解器 ( $\mathrm{H}$ 型电解池、流动电 解池和膜电极电解池) 的研究进展, 基于电流密 度、法拉第效率、能量效率和稳定性等四个关键性 
能参数, 比较和讨论了不同电解器构型的优缺点 及其对 $\mathrm{CO}_{2}$ 电还原性能的影响, 指出膜电极电解器 被认为是最具工业应用前景的技术方案。孙振宇 等 ${ }^{9}$ 构建了一系列 $\mathrm{Cu} / \mathrm{CeO}_{2}$ 纳米催化剂, 通过利用 $\mathrm{Cu}$ 和不同形状的 $\mathrm{CeO}_{2}$ 纳米晶之间的相互作用, 实 现了对电催化 $\mathrm{CO}_{2}$ 还原产乙烯性能的有效调控。

利用太阳能实现 $\mathrm{CO}_{2}$ 还原是模拟自然界光合作 用、实现 $\mathrm{CO}_{2}$ 转化的最理想途径。因其大比表面积、 大量低配位表面原子, 以及从内部到表面转移距离 更短等性能优势, 超薄层状材料在光催化二氧化碳 还原方面显示独特优势。纪红兵等 ${ }^{10}$ 对超薄二维光 催化剂进行了分类, 对其制备方法和光催化 $\mathrm{CO}_{2}$ 还 原机理进行了介绍, 系统总结了这类光催化材料的 最新研究进展。非贵金属配合物作为分子催化剂, 因其价格方面的优势在光催化 $\mathrm{CO}_{2}$ 还原研究方面受

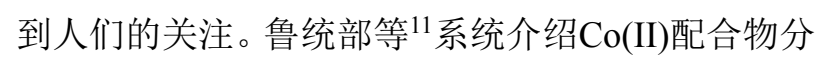
子催化剂在光催化 $\mathrm{CO}_{2}$ 还原方面的最新研究进展, 重点分析了配合物分子结构对催化效率、选择性和 稳定性的影响, 并针对存在的问题提出了 $\mathrm{Co}(\mathrm{II})$ 配 合物分子催化剂的设计思路。在众多光催化材料 中, $\mathrm{CdS}$ 和 $\mathrm{CdSe}$ 是研究较多的两种半导体材料。王 锋等 ${ }^{12}$ 介绍了基于 $\mathrm{CdS}$ 或 $\mathrm{CdSe}$ 纳米材料的光催化还 原二氧化碳的催化体系及其光催化反应机制。

催化剂在 $\mathrm{CO}_{2}$ 还原中起关键作用。因其接近 $100 \%$ 的原子利用率和独特的催化性能, 单原子催 化剂可实现催化 $\mathrm{CO}_{2}$ 加氢选择性转化为一氧化碳、 甲烷、甲醇、甲酸以及 $\mathrm{C}_{2}+$ 化合物等化学品。崔新 江和石峰 ${ }^{13}$ 系统总结了近几年来单原子催化剂电 催化、光催化以及热催化二氧化碳加氢方面的研 究进展, 探讨了单原子催化剂的构效关系及其催 化反应机制。

在本专刊组织期间, 我们收到了一篇关于 $\mathrm{CO}_{2}$ 对全球气温影响的来稿 ${ }^{14}$ 。Dautzenberg博士及其合 作者从全新的角度阐释了由于 $\mathrm{CO}_{2}$ 排放而可能引 起的气温变化。我们认为这篇文章对从事 $\mathrm{CO}_{2}$ 资源 化利用和关注 $\mathrm{CO}_{2}$ 问题的科研工作者具有重要的 参考价值, 因此将此文收录在本专刊中。

二氧化碳还原转化是当前化学领域的前沿研 究课题, 研究成果不断涌现, 在本专刊组织期间, 国内学者在国际重要期刊上发表一系列创新性成 果, 我们遴选了其中的 5 篇作为亮点评述, 与读者 一起分享。

\section{References}

(1) Hua, K.; Liu, X. F.; Wei, B. Y.; Zhang, S.; Wang, H.; Sun Y. H. Acta Phys. -Chim. Sin. 2021, 37 (5), 2009098. [华凯敏, 刘晓放, 魏百银,
张书南, 王慧, 孙予罕. 物理化学学报, 2021, 37 (5), 2009098.] doi: 10.3866/PKU.WHXB202009098

(2) Zhang, X. H.; Cao, Y. W.; Chen, Q. Y.; Shen, C. R.; He, L. Acta Phys. -Chim. Sin. 2021, 37 (5), 2007052. [张雪华, 曹彦伟, 陈琼遥, 沈超仁, 何林. 物理化学学报, 2021, 37 (5), 2007052.] doi: 10.3866/PKU.WHXB202007052

(3) Wang, H.; Wu, Y. Y.; Zhao, Y. F.; Liu, Z. M. Acta Phys. -Chim. Sin. 2021, 37 (5), 2010022. [王欢, 吴云雁, 赵燕飞, 刘志敏. 物理化学 学报, 2021, 37 (5), 2010022.] doi: 10.3866/PKU.WHXB202010022

(4) Wang, Y. Q.; Zhong, Z. X.; Liu, T. K.; Liu, G. L.; Hong, X. L. Acta Phys. -Chim. Sin. 2021, 37 (5), 2007089. [王艳秋, 钟子欣, 刘唐康, 刘国亮, 洪昕林. 物理化学学报, 2021, 37 (5), 2007089.] doi: 10.3866/PKU.WHXB202007089

(5) Li, C. M.; Chen, K.; Wang, X. Y.; Xue, N.; Yang, H. Q. Acta Phys. -Chim. Sin. 2021, 37 (5), 2009101. [李聪明, 陈阔, 王晓月, 薛楠, 杨恒权. 物理化学学报, 2021, 37 (5), 2090101.] doi: 10.3866/PKU.WHXB202009101

(6) Yuan, Q.; Yang, H.; Xie, M.; Cheng, T. Acta Phys. -Chim. Sin. 2021, 37 (5), 2010040. [苑琦, 杨吴, 谢录, 程涛. 物理化学学报, 2021, 37 (5), 2010040.] doi: 10.3866/PKU.WHXB202010040

(7) Meng, Y. C.; Kuang, S. Y.; Liu, H.; Fan, Q.; Ma, X. B.; Zhang, S. Acta Phys. -Chim. Sin. 2021, 37 (5), 2006034. [孟怡辰, 况思宇, 刘 海, 范群, 马新宾, 张生. 物理化学学报, 2021, 37 (5), 2006034.] doi: 10.3866/PKU.WHXB202006034

(8) Gao, D. F.; Wei, P. F.; Li, H. F.; Lin, L.; Wang, G. X.; Bao, X. H. Acta Phys. -Chim. Sin. 2021, 37 (5), 2009021. [高敦峰, 魏鹏飞, 李 合肥, 林龙, 汪国雄, 包信和. 物理化学学报, 2021, 37 (5), 2009021.] doi: 10.3866/PKU.WHXB202009021

(9) Chu, S. L.; Li, X.; Robertson, A. W.; Sun, Z. Y. Acta Phys. -Chim. Sin. 2021, 37 (5), 2009023. [楚森林, 李欣, Robertson, A. W., 孙振宇. 物理 化学学报, 2021, 37 (5), 2009023.] doi: 10.3866/PKU.WHXB202009023

(10) Qin, Z. Z.; Wu, J.; Li, B.; Su, T. M.; Ji, H. B. Acta Phys. -Chim. Sin. 2021, 37 (5), 2005027. [秦祖赠, 吴靖, 李斌, 苏通明, 纪红兵. 物理化学学 报, 2021, 37 (5), 2005027.] doi: 10.3866/PKU.WHXB202005027

(11) Zhang, J. H.; Zhong, D. C.; Lu, T. B. Acta Phys. -Chim. Sin. 2021, 37 (5), 2008068. [张继宏, 钟地长, 鲁统部. 物理化学学报, 2021, 37 (5), 2008068.] doi: 10.3866/PKU.WHXB202008068

(12) Wu, J.; Liu, J.; Xia, W.; Ren, Y. Y.; Wang, F. Acta Phys. -Chim. Sin. 2021, 37 (5), 2008043. [吴进, 刘京, 夏雾, 任颖异, 王锋. 物理化学 学报, 2021, 37 (5), 2008043.] doi: 10.3866/PKU.WHXB202008043

(13) Cui, X. J.; Shi, F. Acta Phys. -Chim. Sin. 2021, 37 (5), 2006080. [崔新江, 石峰. 物理化学学报, 2021, 37 (5), 2006080.] doi: 10.3866/PKU.WHXB202006080

(14) Dautzenberg, F. M.; Lu, Y.; Xu, B. Acta Phys. -Chim. Sin. 2021, 37 (5), 2008066. [Dautzenberg, F. M., 路勇, 徐涁. 物理化学学报, 2021, 37 (5), 2008066.] doi: 10.3866/PKU.WHXB202008066 